\title{
Spermatozoa in an abdominal lymph node after vasectomy in a man
}

\author{
R. Y. Ball, C. P. E. Naylor and M. J. Mitchinson \\ Department of Pathology, Tennis Court Road, Cambridge CB2 IQP, and Department of Morbid \\ Anatomy and Histopathology, Addenbrooke's Hospital, Hills Road, Cambridge CB2 2QR, U.K.
}

\begin{abstract}
Summary. Spermatozoa were found in a para-aortic lymph node 1 year after vasectomy in a man undergoing laparotomy. Such access of spermatozoa to the lymph nodes is one route by which autosensitization against spermatozoa could arise.
\end{abstract}

\section{Introduction}

The production of auto-antibodies against spermatozoa is a well-recognized sequel of vasectomy in man and other animals and occurs spontaneously in a small percentage of infertile men (Rümke \& Hellinga, 1959). The mechanism by which such auto-immunity occurs is unknown. This paper describes the hitherto unreported finding of spermatozoa in an abdominal lymph node of a vasectomized man.

\section{Observations}

A 32-year-old male had recently noticed a lump in the neck and biopsy of a cervical lymph node had shown lymphocyte-predominant Hodgkin's disease, a malignant lymphoproliferative disorder (Symmers, 1978). On admission to Addenbrooke's Hospital, Cambridge, for staging investigations, he was completely well in himself. Vasectomy had been performed 1 year previously. Physical examination was unremarkable except for a few, small palpable lymph nodes in the inguinal regions and in the left supraclavicular fossa and an atrophic left testis. Standard investigations, including lymphangiography and examination of the bone marrow, produced results within the normal ranges. Chest X-ray indicated lymphomatous involvement of the mediastinal lymph nodes but staging laparotomy with splenectomy and biopsy of the liver and lymph nodes failed to reveal intra-abdominal disease.

A lymph node excised from the region of the left renal artery and processed for histological examination by standard techniques was remarkable in that it contained innumerable spermatozoa. Many lay free in the sinuses (Pl. 1, Fig. 1) but a large number had been phagocytosed by macrophages (PI. 1, Fig. 2). The spermatozoa extended from the marginal sinus, where they were most numerous, throughout the nodal pulp. The sperm heads had a normal morphology, were deeply haematoxyphil and were acid-alcohol-fast. They showed little obvious evidence of degeneration. The node contained a few germinal centres but no other noteworthy features except a few macrophages containing PAS-positive material. A few such cells also contained phagocytosed spermatozoa.

\section{Discussion}

It is accepted that most men develop antibodies against spermatozoa after vasectomy (Faulk \& Fox, 1982). The mechanism of sensitization is unclear but must involve the presentation of sperm 
antigens to immunocompetent cells. Possible modes of egress of sperm antigens from the excurrent ducts include: intraluminal phagocytosis of spermatozoa by macrophages which then migrate into the interstitium (Mitchinson, Sherman \& Stainer-Smith, 1975); rupture of the duct, associated with a vasectomy site or otherwise, thus releasing spermatozoa into the interstitium and exciting a granulomatous inflammatory reaction; and leakage of soluble antigens following sperm disintegration within the lumen.

Direct access of spermatozoa to regional lymph nodes has received little attention although spermatozoa have been seen within lymphatic vessels adjacent to spermatic granulomata of the epididymis (Friedman \& Garske, 1949; Glassy \& Mostofi, 1956; King, 1956). The present case clearly demonstrates that spermatozoa may enter the lymph and reach regional nodes. Although the left testis was atrophic clinically, the spermatozoa may have been derived from the right side since some testicular lymphatic vessels cross the midline in a proportion of normal men (McBrien, Edwards \& Kinmonth, 1972). Most of the spermatozoa were free within the lymph node sinuses but some had already been phagocytosed. The fact that such phagocytosis occurs rapidly in vitro and is followed by sperm disintegration over the course of a few days (Ball \& Mitchinson, 1977) implies that the spermatozoa must have arrived in the node relatively recently. However, immunological abnormalities are present in Hodgkin's disease (Symmers, 1978; Haywood, 1982) and the handling of micro-organisms and other cells by lymph node macrophages may be disturbed. Direct access to lymph nodes is clearly one means by which auto-sensitization against spermatozoa could arise.

We thank Miss Brenda Disbrey and staff for the histological sections, Dr D. G. Bratherton for permission to publish the case, and Miss P. Coe for typing the manuscript. R.Y.B. is funded by an Elmore Medical Research Studentship and St John's College, Cambridge.

\section{References}

Ball, R.Y. \& Mitchinson, M.J. (1977) Degradation of phagocytosed spermatozoa by mouse peritoneal macrophages in vitro. J. Reprod. Fert. 49, 409-411

Faulk, W.P. \& Fox, H. (1982) Reproductive Immunology. In Clinical Aspects of Immunology, 4th edn, ch. 36, pp. 1104-1150. Eds P. J. Lachmann \& D. K. Peters. Blackwell, Oxford.

Friedman, N.B. \& Garske, G.L. (1949) Inflammatory reactions involving sperm and the seminiferous tubules: extravasation, spermatic granulomas and granulomatous orchitis. J. Urol. 62, 363-374.

Glassy, F.J. \& Mostofi, F.K. (1956) Spermatic granulomas of the epididymis. Am. J. clin. Path. 26, 13031313.

Haywood, A. (1982) Immunodeficiency. In Clinical Aspects of Immunology, 4th edn, ch. 63, pp. 1658-1712. Eds P. J. Lachmann \& D. K. Peters. Blackwell, Oxford.
King, E.S.J. (1956) Spermatozoal invasion of the epididymis. J. Path. Bact. 70, $459-467$.

McBrien, M.P., Edwards, J.M. \& Kinmonth, J.B. (1972) Lymphography of the testis and its adnexa in the normal and in idiopathic hydrocoele. Arch. Surg. 104, $820-825$.

Mitchinson, M.J., Sherman, K.P. \& Stainer-Smith, A.M. (1975) Brown patches in the epididymis. J. Path. 115, $57-62$.

Rümke, Ph. \& Hellinga, G. (1959) Autoantibodies against spermatozoa in sterile men. Am. J. clin. Path. 32, 357-363.

Symmers, W.StC. (1978) The lymphoreticular system. In Systemic Pathology, 2nd edn, ch. 9, pp. 506-891. Ed. W. St C. Symmers. Churchill Livingstone, Edinburgh.

Received 12 May 1982 
PLATE 1
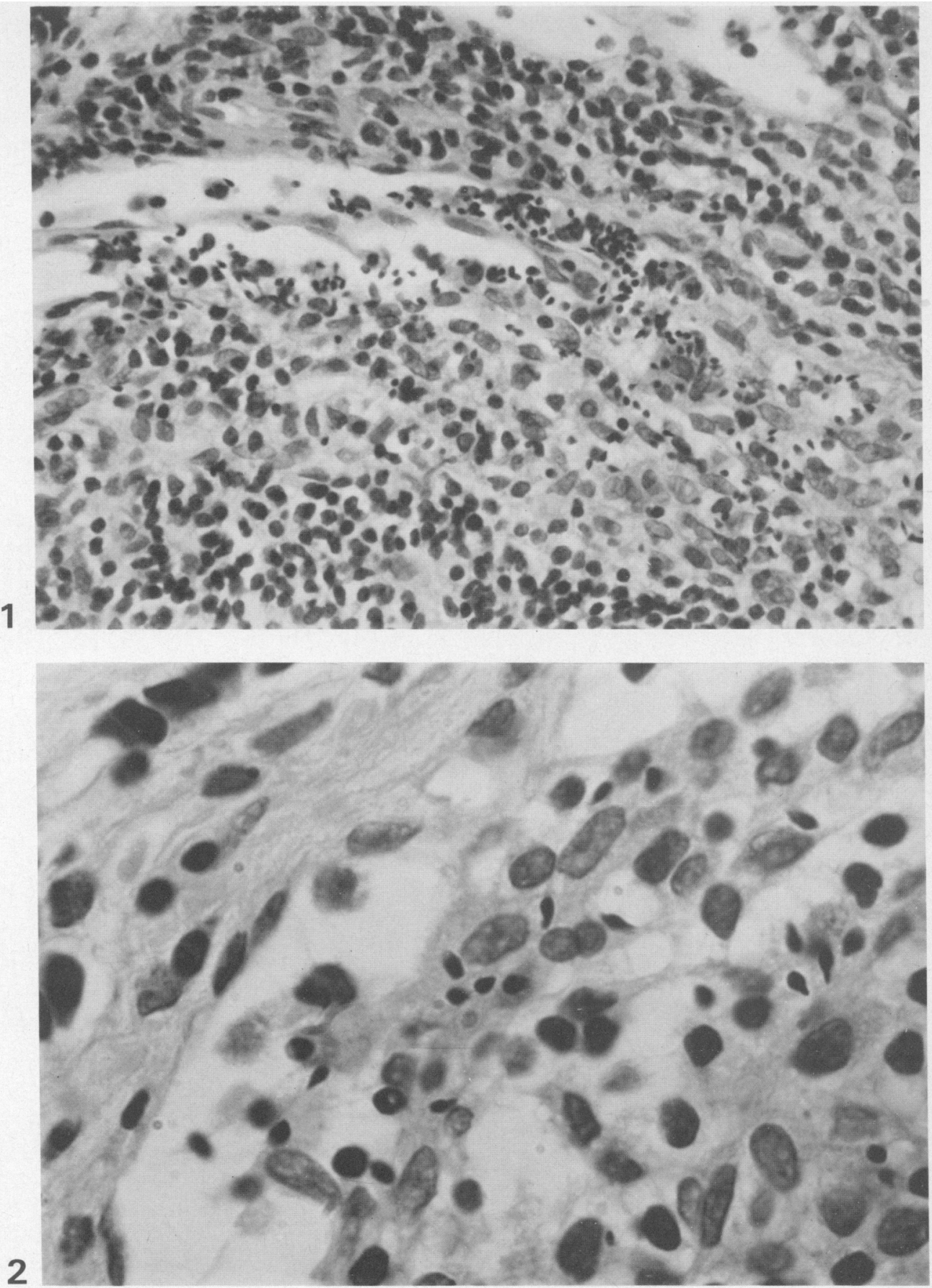

Fig. 1. Human para-aortic lymph node showing numerous haematoxyphil sperm heads lying in one of the sinuses. $\mathrm{H} \& \mathrm{E}, \times 500$.

Fig. 2. Human para-aortic lymph node. Most of the sperm heads have clearly been phagocytosed by sinus macrophages and some are surrounded by a clear halo representing the phagocytic vacuole. $\mathrm{H} \& \mathrm{E}, \times 1250$. 